\title{
Winter measurements of oceanic biogeochemical parameters in the Rockall Trough (2009-2012)
}

\author{
T. McGrath ${ }^{1,2}$, C. Kivimäe ${ }^{3}$, E. McGovern ${ }^{1}$, R. R. Cave ${ }^{2}$, and E. Joyce ${ }^{1}$ \\ ${ }^{1}$ Marine Institute, Rinville, Oranmore, Galway, Ireland \\ ${ }^{2}$ Earth and Ocean Science, School of Natural Sciences, National University of Ireland, Galway, Ireland \\ ${ }^{3}$ National Oceanography Centre, University of Southampton Waterfront Campus, European Way, \\ Southampton SO14 3ZH, UK \\ Correspondence to: T. McGrath (triona_mcgrath@ @otmail.com)
}

Received: 1 July 2013 - Published in Earth Syst. Sci. Data Discuss.: 2 August 2013

Revised: 26 November 2013 - Accepted: 27 November 2013 - Published: 11 December 2013

\begin{abstract}
This paper describes the sampling and analysis of biogeochemical parameters collected in the Rockall Trough in January/February of 2009, 2010, 2011 and 2012. Sampling was carried out along two transects, one southern and one northern transect each year. Samples for dissolved inorganic carbon (DIC) and total alkalinity (TA) were taken alongside salinity, dissolved oxygen and dissolved inorganic nutrients (total-oxidized nitrogen, nitrite, phosphate and silicate) to describe the chemical signatures of the various water masses in the region. These were taken at regular intervals through the water column. The data are available on the CDIAC database, http://cdiac.ornl.gov/ftp/oceans/Rockall_Trough/.
\end{abstract}

\section{Data coverage and parameter measured}

Repository-Reference: doi:10.3334/CDIAC/OTG.ROCKALL_TROUGH_2012

Available at:

http://cdiac.ornl.gov/ftp/oceans/Rockall_Trough/

Coverage: $52.8-56.2^{\circ} \mathrm{N}, 18.5-9^{\circ} \mathrm{W}$

Location Name: Rockall Trough

Date/Time Start: 5 February 2009

Date/Time End: 12 January 2012

\section{Introduction}

Between February 2008 and August 2010 a pilot project to initiate research in ocean carbon processes in Irish marine waters was carried out jointly by the National University of Ireland, Galway (NUIG), and the Marine Institute, Ireland (MI). The project titled Increased Atmospheric $\mathrm{CO}_{2}$ on Ocean Chemistry and Ecosystems was carried out under the Sea Change strategy with the support of the Marine Institute and the Marine Research Sub-Programme of the National Development Plan 2007-2013 (O'Dowd et al.,
2011). Through collaboration with annual MI winter surveys, a range of biogeochemical parameters were measured across the Rockall Trough in January or February of 2009, 2010, 2011 and 2012. The Rockall Trough plays an important role in the global thermohaline circulation as it provides a pathway for warm saline waters of the upper North Atlantic to reach the Nordic Seas. There is also a complex interaction of water masses of different origins in the trough (McGrath et al., 2012b) and therefore it is an important region in oceanclimate research. The 2009 and 2010 data have recently been compared with data measured in the trough in the 1990s by the World Ocean Circulation Experiment (McGrath et al., 2012a, b).

\section{Data provenance}

All surveys were carried out on the RV Celtic Explorer; see exact dates in Table 2. While conductivity, temperature and depth (CTD) data are available for every station in Fig. 1, inorganic carbonate parameters were generally measured every second station in 2009 and 2010. In 2011, only 5 surface carbonate samples were taken for inter-laboratory comparison 
Table 1. List of parameters from the Rockall Trough as seen in the CDIAC database.

\begin{tabular}{|c|c|c|c|}
\hline Data Product Parameter Name & $\begin{array}{l}\text { Exchange File } \\
\text { Parameter Name }\end{array}$ & $\begin{array}{l}\text { Exchange File } \\
\text { Flag Name }\end{array}$ & Units \\
\hline Station & STNNBR & & \\
\hline Cast number & CASTNO & & \\
\hline Bottle number & BTLNBR & BTLNBR_FLAG_W & \\
\hline Year/month/day & DATE & & \\
\hline Time & TIME & & \\
\hline Latitude & LATITUDE & & decimal degrees \\
\hline Longitude & LONGITUDE & & decimal degrees \\
\hline Depth & DEPTH & & metres \\
\hline Pressure & CTDPRS & & decibars \\
\hline Temperature & CTDTMP & & degrees Celsius \\
\hline CTD Salinity & CTDSAL & CTDSAL_FLAG_W & \\
\hline Salinity & SALNTY & SALNTY_FLAG_W & \\
\hline CTD Oxygen & CTDOXY & CTDOXY_FLAG_W & micromole $\mathrm{kg}^{-1}$ \\
\hline Dissolved oxygen & OXYGEN & OXYGEN_FLAG_W & micromole $\mathrm{kg}^{-1}$ \\
\hline Dissolved inorganic silicate & SILCAT & SILCAT_FLAG_W & micromole $\mathrm{kg}^{-1}$ \\
\hline Dissolved inorganic nitrate & NITRAT & NITRAT_FLAG_W & micromole $\mathrm{kg}^{-1}$ \\
\hline Dissolved inorganic nitrite & NITRIT & NITRIT_FLAG_W & micromole $\mathrm{kg}^{-1}$ \\
\hline Dissolved inorganic phosphate & PHSPHT & PHSPHT_FLAG_W & micromole $\mathrm{kg}^{-1}$ \\
\hline Dissolved inorganic carbon & TCARBN & TCARBN_FLAG_W & micromole $\mathrm{kg}^{-1}$ \\
\hline Total alkalinity & ALKALI & ALKALI_FLAG_W & micromole $\mathrm{kg}^{-1}$ \\
\hline
\end{tabular}

with samples analysed at Scripps Institution of Oceanography (SIO), while in 2012 carbonate samples were taken at every station along the southern transect. Salinity and nutrients were measured along both transects every year. Stations were approximately $27 \mathrm{~km}$ apart, except for along the shelf edge where there was greater horizontal sampling resolution.

\section{Methods and quality control procedures}

\subsection{Hydrography}

A Seabird CTD profiling instrument (SBE 911) with water bottles on a rosette was used on each survey. Temperature and conductivity sensors were sent to Seabird annually for calibration. On every survey there was a primary and secondary temperature and conductivity sensor set on the CTD, which were compared to ensure they match to a high level of precision. Processed salinity sensor data were also compared with the discrete water samples analysed on a Guildline Portasal salinometer (Model 8410A) at the MI. On every survey the sensor-laboratory comparison resulted in an $r^{2}$ value greater than 0.999 , while the average difference between salinity sensor and bottle data was -0.010 for CE0903, -0.003 for CE10002, -0.004 for CE11001 and -0.013 for CE12001 (where the sensor data was consistently lower than the bottle data). The CTD sensor data will be calibrated with these offsets in the second version of the GLODAP database (Key et al., 2004), currently being developed. An SB43 oxygen sensor was deployed with the CTD, which was also calibrated annually with the manufacturer. On surveys where oxygen samples were taken, the oxygen sensor data was calibrated with the laboratory results.

\subsection{Collection of water samples for chemical analysis}

Water samples were collected in Niskin bottles attached to the CTD rosette. Two Niskin bottles were filled at every depth. At the beginning of every survey all Niskin bottles and taps were checked for leaks, which were fixed prior to sampling. Samples were drawn from the deepest depths first, and chemical parameters were drawn from the first Niskin at each depth in the following order: dissolved oxygen, dissolved inorganic carbon and total alkalinity, dissolved nutrients and salinity.

\subsection{Dissolved inorganic carbon and total alkalinity}

The Guide to Best Practices for Ocean $\mathrm{CO}_{2}$ measurements (Dickson et al., 2007), which describes the standard methods now in use for the determination of these parameters, was followed for the sampling and analysis of DIC (dissolved inorganic carbon) and TA (total alkalinity).

\subsubsection{Sampling}

DIC and TA were generally analysed from the same bottle; a $500 \mathrm{~mL}$ Schott Duran borosilicate glass bottle with ground glass stopper. Silicone tubing was attached to the tap of the Niskin bottle, sample water was allowed to flow through the tubing to remove any air bubbles and the bottle 
Table 2. Details of surveys with number of chemistry samples taken on each.

\begin{tabular}{lccccccc}
\hline Survey & EXPOCODE & Date & DIC & TA & O $_{2}$ & NUT & SAL \\
\hline CE0903 & 45CE20090206 & 5-15 Feb 2009 & 64 & 64 & & 144 & 133 \\
CE10002 & 45CE20100209 & 5-17 Feb 2010 & 95 & 95 & 190 & 333 & 266 \\
CE11001 & 45CE20110103 & 3-10 Jan 2011 & 5 & 5 & 145 & 204 & 183 \\
CE12001 & 45CE20120105 & 5-12 Jan 2012 & 75 & 75 & & 165 & 165 \\
\hline
\end{tabular}
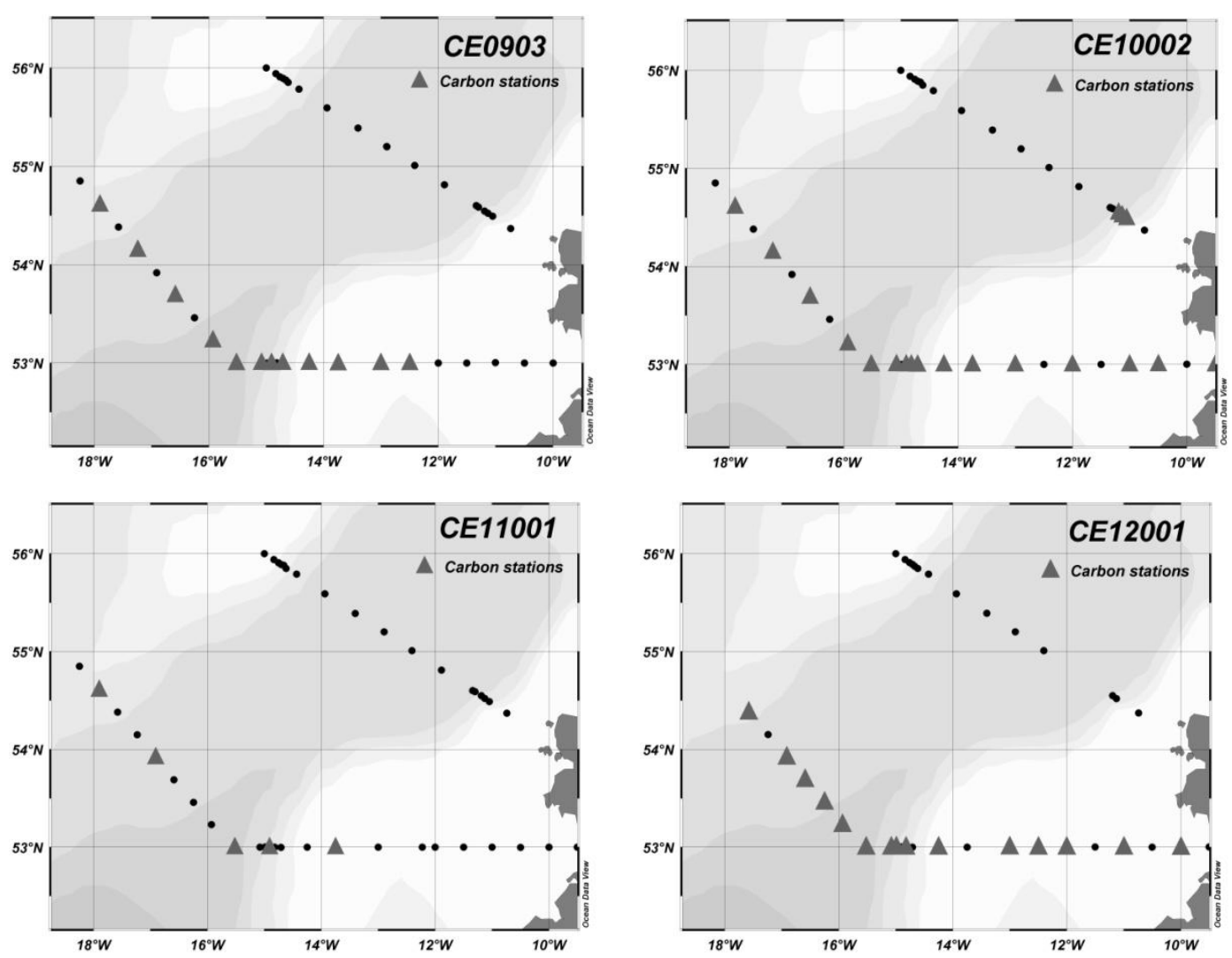

Figure 1. Station positions from the surveys CE0903 (February 2009), CE10002 (February 2010), CE11001 (January 2011 ) and CE12001 (January 2012). Stations with triangle symbols are where carbonate parameters were measured. Note in CE11001 only surface samples were taken, in other years samples were taken through the water column.

was first rinsed before filling slowly from the bottom. The water was overflowed by approximately 1 bottle volume. Using a pipette, a headspace $(\sim 2 \mathrm{~mL})$ was left in the top of the bottle to allow for water expansion, then $0.1 \mathrm{~mL}$ of saturated mercuric chloride solution was added to poison the sample. The glass stopper was greased with Apiezon L Grease before arriving at the station. After the sample was poisoned, excess water was wiped from the neck of the bottle and the stopper was twisted slowly into place, squeezing the air out of the grease. Finally the stopper was clamped in place using 3 thick elastic bands. The bottle was inverted several times to disperse the mercuric chloride and the sample was stored in a cool, dark location and analysed on land. Any seawater or materials contaminated with mercuric chloride during sample collection and analysis were collected and disposed of by a chemical waste disposal company in full compliance with hazardous waste regulations.

In CE10002, 13 of the 95 DIC and TA samples were collected in separate containers (by the same method described above) due to insufficient borosilicate glass bottles. DIC was collected in $250 \mathrm{~mL}$ amber glass bottles with ground glass stoppers and TA was collected in $500 \mathrm{~mL}$ high-density polyethylene (HDPE) bottles with screw caps. As TA concentration is not affected by $\mathrm{CO}_{2}$ in the atmosphere and biological activity was at a minimum due to winter sampling, it was not necessary to seal the TA samples in the same manner as DIC. These samples were consistent with the vertical profile from that year and with other surveys in the region. 


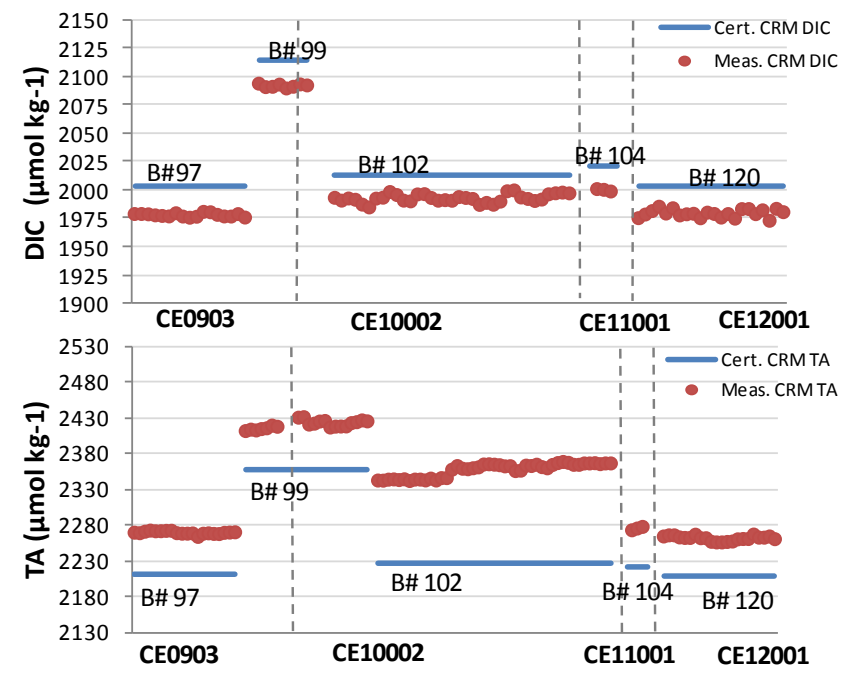

Figure 2. DIC and TA CRM measured values plotted against certified values for each of the surveys. Dashed lines indicate a new survey.

\subsubsection{Analysis}

DIC was measured on a VINDTA-3C (Versatile Instrument for the Determination of Titration Alkalinity) system with UIC coulometer (Dickson et al., 2007). A known volume of sample is acidified with phosphoric acid in order to convert all dissolved inorganic carbon to $\mathrm{CO}_{2}$ and the resulting $\mathrm{CO}_{2}$, forced out of the sample using nitrogen as a carrier gas, is titrated coulometrically (Johnson et al., 1987, 1993).

TA was analysed by potentiometric titration with $0.1 \mathrm{M}$ hydrochloric acid, also on the VINDTA 3C (Mintrop et al., 2000). During the titration the bases in the TA definition (Dickson, 1981) are transferred to their acidic forms and the titration is monitored by a $\mathrm{pH}$ electrode that measures the electromotive force (emf). The process is controlled by the LabVIEW $^{\mathrm{TM}}$ software and the endpoint is determined by the change in $\mathrm{pH}$ against the volume of acid added to the solution. The result of the titration is evaluated with curve fitting (Mintrop et al., 2000).

\subsubsection{Quality control}

The accuracy of both DIC and TA analysis was ensured by analysing duplicate certified reference materials (CRMs) before every batch of samples. CRMs were provided by A. Dickson, Scripps Institution of Oceanography, USA (Dickson et al., 2003). If many samples (>10) were run in a single batch, another duplicate CRM was run at the end of the day. The mean of the measured CRM results was used to calculate a CRM correction factor to adjust DIC and TA sample results for any offset in the VINDTA.

CRM correction factor $=$ certified value $/$ measured value
Table 3. Accuracy and precision of DIC and TA in $\mu \mathrm{mol} \mathrm{kg}^{-1}$ for each of the surveys, calculated as the average and standard deviation, respectively of the differences between duplicate samples, where $n$ is the number of duplicate samples.

\begin{tabular}{lccccc}
\hline & $\begin{array}{c}\text { Accuracy } \\
\text { DIC }\end{array}$ & $\begin{array}{c}\text { Precision } \\
\text { DIC }\end{array}$ & $\begin{array}{c}\text { Accuracy } \\
\text { TA }\end{array}$ & $\begin{array}{c}\text { Precision } \\
\text { TA }\end{array}$ & $n$ \\
\hline CE0903 & 2 & 2 & 1 & 1 & 64 \\
CE10002 & 3 & 2 & 1 & 1 & 60 \\
CE11001 & 1 & 1 & 2 & 2 & 4 \\
CE12001 & 2 & 1 & 2 & 2 & 43 \\
\hline
\end{tabular}

Sample results were then multiplied by the daily correction factors. The CRM results are shown in Fig. 2. It is unclear why the TA CRMs for Batch 102 used for CE10002 had a slightly larger offset than other batches. Vertical profiles of final TA concentrations from this survey were cross-checked with TA profiles from CE12001 and two WOCE (World Ocean Circulation Experiment) surveys in the same region (McGrath et al., 2012a). All suggest that there is no problem/offset in the TA results generated from this batch. By using the CRM correction factor, results were corrected for the larger offset in the instrument during this time. Duplicate samples from the same bottle were run every second sample, while replicate bottles were taken for 5-10\% of the total sample number from each survey. The accuracy and precision of the measurements were calculated as the average and standard deviation, respectively of the differences between duplicate samples, Table 3.

\section{DIC and TA storage experiment}

A storage experiment was carried out to investigate if storing samples for a prolonged length of time had an effect on the DIC and TA concentration. On 21 May 2010, twentysix $500 \mathrm{~mL}$ Schott Duran bottles were filled with water taken from $448 \mathrm{~m}$ deep along the shelf edge $\left(10.0322^{\circ} \mathrm{W}\right.$, $55.2565^{\circ} \mathrm{N}$ ). All bottles were filled by the author (T. McGrath), while a colleague poisoned, greased and sealed the bottles. Six $250 \mathrm{~mL}$ glass (not-borosilicate) bottles, used for DIC only, were also tested to ensure these bottles did not affect the stored samples differently than the Schott Duran bottles. All samples were poisoned with mercuric chloride, stored at $4{ }^{\circ} \mathrm{C}$ in a dark fridge until they were analysed. The first set of samples $(T=0)$ was run on 29 May 2010 and a new set of samples was run monthly for the first 7 months (with one exception), with subsequent analysis every 2-3 months. A duplicate of every bottle was run, and the final result for each bottle below (Fig. 3) is an average of the duplicate values. The 8 days from when the samples were drawn until $T=0$ should not affect the initial concentration as samples are not expected to be contaminated that quickly if the bottles are sealed correctly (personal communication with staff at Andrew Dickson's laboratory at SIO, 2013). 


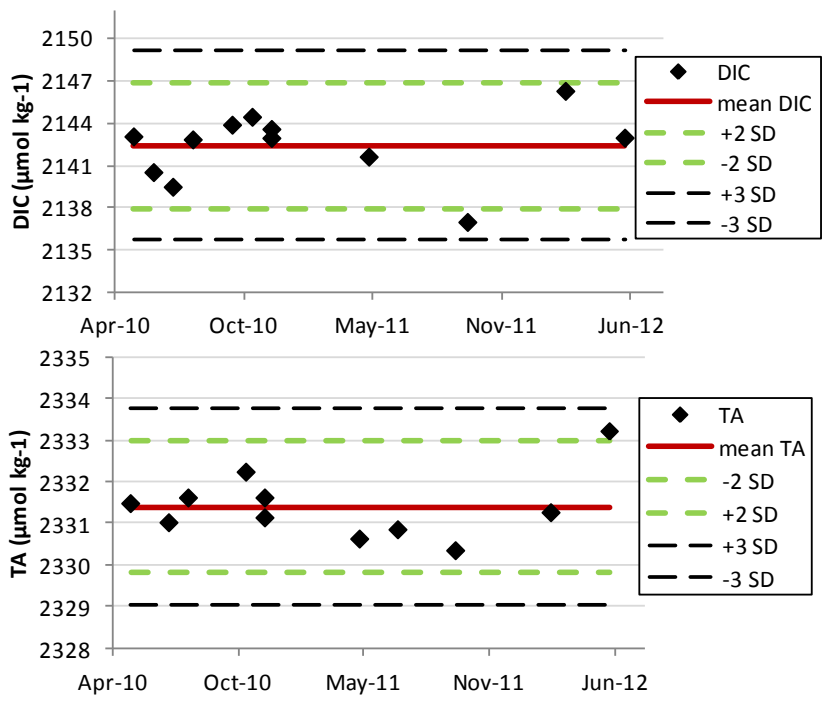

Figure 3. Average monthly (from at least 2 sample bottles) DIC and TA concentrations over $2 \mathrm{yr}$ of storage. The mean and standard deviations for DIC were based on the first year of storage when concentrations were within $\pm 3 \mu \mathrm{mol} \mathrm{kg}{ }^{-1}$ around the mean, while both years of storage results were used for TA as they were all within $\pm 2 \mu \mathrm{mol} \mathrm{kg}^{-1}$ of the mean.

The average DIC at $T=0$ was $2143 \mu \mathrm{mol} \mathrm{kg}^{-1}$ (analysed from 4 replicate sample bottles, where a duplicate was run from each bottle). The average DIC over the first full year of storage was $2142 \mu \mathrm{mol} \mathrm{kg}$, and variation around the mean is less than $\pm 3 \mu \mathrm{mol} \mathrm{kg}{ }^{-1}$. Both Schott Duran and soft glass bottles had similar concentrations after a year. There was greater variability in DIC concentrations in the second year of storage, results from one month (July 2011) were discarded as concentrations were over $10 \mu \mathrm{mol} \mathrm{kg} \mathrm{kg}^{-1}$ below the mean.

The average TA at $T=0$ was $2331 \mu \mathrm{mol} \mathrm{kg}-1$, and remained constant for the 26 months of storage, with variation of less than $\pm 2 \mu \mathrm{mol} \mathrm{kg}{ }^{-1}$ around the mean. Results from one month (June 2010) were discarded as concentrations were $8 \mu \mathrm{mol} \mathrm{kg}{ }^{-1}$ above all other months and appear to be a oneoff error.

Results indicate that, while TA samples can be stored for at least $2 \mathrm{yr}$, DIC samples should be analysed within $1 \mathrm{yr}$ of sampling. All samples collected in the Rockall Trough were analysed well within 1 yr of sampling.

\section{Cross validation of DIC and TA analysed at Scripps Institution of Oceanography}

In the survey CE11001 across the Rockall Trough in January 2011, a batch of surface DIC and TA samples was sent to Scripps Institution of Oceanography, USA, for analysis. Five replicates of these samples were analysed by the author (T. McGrath) at NUIG, where a duplicate was run for every sample. DIC and TA concentrations from NUIG were within $\pm 3.1 \mu \mathrm{mol} \mathrm{kg}^{-1}$ and $\pm 1.3 \mu \mathrm{mol} \mathrm{kg}^{-1}$, respectively, of those analysed at SIO.

\subsection{Dissolved inorganic nutrients}

\subsubsection{Sampling}

All equipment involved in the sampling and filtration of nutrient samples was acid-cleaned in $10 \%$ hydrochloric acid prior to sampling (Grasshoff et al., 1999). Water for nutrient samples was collected from the Niskin bottle in $1 \mathrm{~L} \mathrm{HDPE}$ bottles. The $1 \mathrm{~L}$ bottles were first rinsed three times with sample water before filling. The sample was filtered through a $0.40 \mu \mathrm{m}$ polycarbonate filter and the filtrate was poured into two $50 \mathrm{~mL}$ polypropylene tubes. The tubes were immediately frozen upright at $-20^{\circ} \mathrm{C}$ and analysed on land.

\subsubsection{Analysis}

Seawater samples were analysed for total oxidized nitrogen $(\mathrm{TOxN})$, nitrite, silicate and phosphate on a Skalar San ${ }^{++}$ continuous flow analyser at the Marine Institute (Grasshoff et al., 1999). The Skalar $\mathrm{San}^{++}$System uses automatic segmented flow analysis where a stream of reagents and samples, segmented with air bubbles, is pumped through a manifold to undergo treatment such as mixing and heating before entering a flow cell to be detected. The sample is pumped into the system and split into 4 channels where it is mixed with reagents. The reagents act to develop a colour, which is measured as an absorbance through a flow cell at a given wavelength.

\section{$\mathrm{TOxN}$}

The Skalar method for the determination of TOxN is based on Greenberg et al. (1980), ISO 13395 (1996), Navone (1964) and Walinga et al. (1989). The sample is first buffered at a $\mathrm{pH}$ of 8.2 , with a buffer reagent made of ammonium chloride and ammonium hydroxide solution, and is then passed through a column containing granulated copper-cadmium to reduce nitrate to nitrite. The nitrite, originally present plus reduced nitrate, is determined by diazotizing with sulfanilamide and coupling with $N$-(1-naphthyl)ethylenediamine dihydrochloride to form a strong reddish-purple dye which is measured at $540 \mathrm{~nm}$.

\section{Nitrite}

The Skalar method for the determination of nitrite is based on EPA (1974), Greenberg et al. (1980) and ISO 13395 (1996), where the diazonium compounds formed by diazotizing of sulfanilamide by nitrite in water under acidic conditions (due to phosphoric acid in the reagent) is coupled with $N$-(1-naphthyl)ethylenediamine dihydrochloride to produce a reddish-purple colour which is measured at $540 \mathrm{~nm}$. 
Table 4. Limit of detection (LOD), limit of quantification (LOQ), both in $\mu \mathrm{molL}^{-1}$, and uncertainty of measurement (UCM) for the nutrient analysis. The ranges given are the linear calibration ranges, concentrations that fall above these are diluted into the linear range.

\begin{tabular}{lcccl}
\hline & LOD & LOQ & UCM & Ranges \\
\hline TOxN & 0.02 & 0.26 & $2.3 \%$ & LOQ-15 \\
Nitrite & 0.01 & 0.04 & $6.7 \%$ & LOQ-1.5 \\
Silicate & 0.03 & 0.38 & $0.5 \%$ & LOQ-15 \\
Phosphate & 0.01 & 0.16 & $1.3 \%$ & LOQ-1.5 \\
\hline
\end{tabular}

\section{Silicate}

The Skalar method for the determination of silicate is based on Babulak and Gildenberg (1973), ISO 16264 (2002) and Smith and Milne (1981). The sample is acidified with sulfuric acid and mixed with an ammonium heptamolybdate solution forming molybdosilicic acid. This acid is reduced with $\mathrm{L}(+)$ ascorbic acid to a blue dye, which is measured at $810 \mathrm{~nm}$. Oxalic acid is added to avoid phosphate interference.

\section{Phosphate}

The Skalar method for the determination of phosphate is based on Boltz and Mellon (1948), Greenberg et al. (1980), Walinga et al. (1989) and ISO 15681-2 (2003), where ammonium heptamolybdate and potassium antimony (III) oxide tartrate react in an acidic medium (with sulfuric acid) with diluted solutions of phosphate to form an antimony-phosphomolybdate complex. This complex is reduced to an intensely blue-coloured complex by $\mathrm{L}(+)$ ascorbic acid and is measured at $880 \mathrm{~nm}$.

Based on the daily calibration standards, concentrations of nutrients can be quantified up to the maximum calibration standard concentration. If sample concentrations fall above this range (Table 4), they must be diluted with artificial seawater.

\subsubsection{Nutrient's quality control}

The accuracy of the nutrient analysis was ensured by running Eurofins CRMs (http://www.eurofins.dk/dk/milj0/ reference-materialer.aspx) with every batch of samples and controlled using quality control (QC) charts according to best practice as per ISO 17025. The system is also calibrated in every run using seven calibration standards made up daily in the laboratory. A replicate of every sample is analysed and the relative percent difference (RPD: difference between the two values/mean $\times 100$ ) of the results greater than the limit of quantification should be $\leq 10$.

To assess the accuracy of the nutrient methods and procedures the MI participates in the QUASIMEME laboratory quality control programme (www.quasimeme.org). Test materials, analysed twice a year, have a large range of concen-
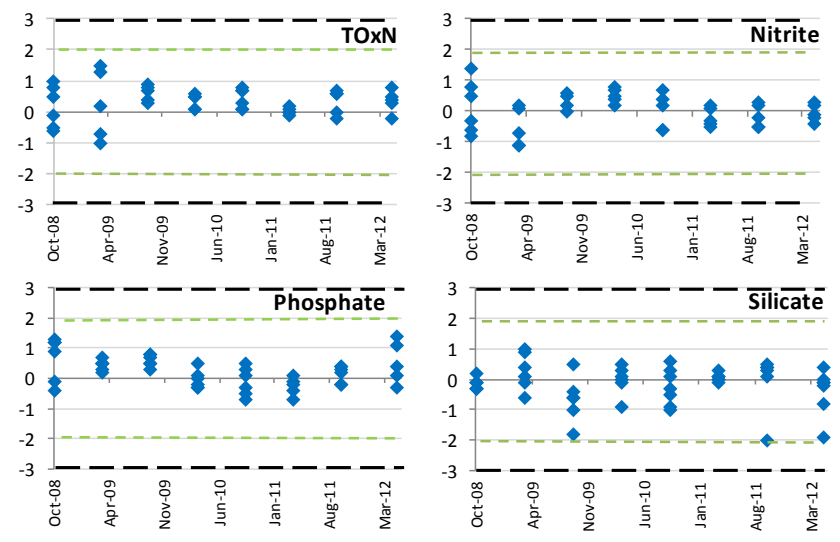

Figure 4. $z$ scores of 8 QUASIMEME rounds of nutrients in the marine environment between October 2008 and May 2012, where the green dashed lines indicate a $z$ score of 2 . The dashed black line at a $z$ score of \pm 3 designates unsatisfactory performance. Most of the QUASIMEME samples were in the range of oceanic values measured in the Rockall Trough.

trations from below the detection limit to high concentrations that have to be diluted. The laboratory performance is expressed with a $z$ score where $|z|<2$ is considered acceptable, where $z$ is the difference between the laboratory result and the assigned value divided by the total error (Cofino and Wells, 1994). Between October 2008 and May 2012 the MI participated in 8 rounds of QUASIMEME proficiency testing scheme exercises (51 samples) for nutrients in the marine environment. The average $z$ score for all nutrients was $<0.5$, see Fig. 4. The MI is accredited to ISO 17025 for nutrient analysis in seawater and is audited annually by the Irish National Accreditation Board, INAB.

\subsection{Salinity}

\subsubsection{Sampling}

Salinity samples were collected in clear glass salinity bottles with plastic screw caps. The bottle was first rinsed three times with the sample water before filling up to the shoulder of the bottle. The necks of the bottles were dried well with clean Kimwipes to prevent salt crystals forming on the top. A plastic insert was then placed into the bottle to produce a tight seal to prevent evaporation, followed by closing the bottle with the screw cap. Samples were stored upright at room temperature.

\subsubsection{Analysis}

Salinity was analysed on a Guildline Portasal salinometer at the MI, where 4 electrode conductivity cells suspended in a temperature-controlled bath measure the conductivity of the sample. The conductivity is related to salinity by calibration from a known standard. Two consecutive conductivity readings within 0.00002 units of each other must be 


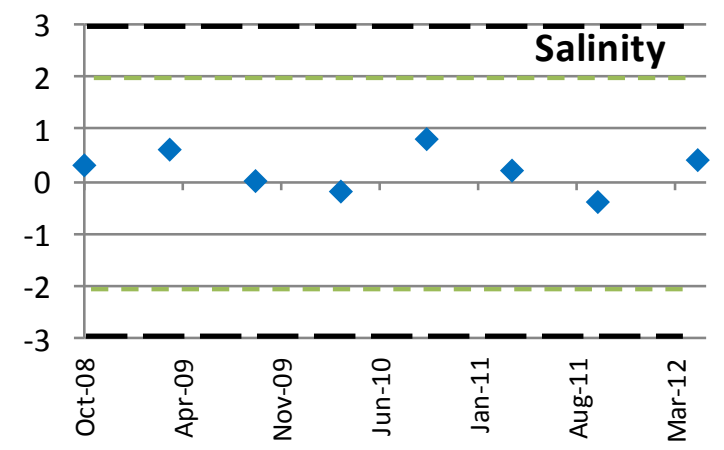

Figure 5. $z$ scores of 8 QUASIMEME rounds of salinity in the marine environment between October 2008 and May 2012, where the green dashed lines indicate a $z$ score of 2 . The dashed black line at a $z$ score of \pm 3 designates unsatisfactory performance.

taken before the salinity can be recorded. The temperature of the salinometer water bath must be set and stabilized to $\sim 1-2{ }^{\circ} \mathrm{C}$ above ambient room temperature and samples must reach room temperature before analysis.

\subsubsection{Salinity quality control}

IAPSO (International Association for the Physical Sciences of the Oceans) seawater standards from OSIL (Ocean Scientific International Ltd) are used to calibrate the instrument daily and run as CRMs with every batch of samples. A Pseries IAPSO standard (salinity $~ 35$ ) is used to calibrate the system and is run every $4 \mathrm{~h}$ during analysis and at the end of the days' analysis. Deionized water (salinity $=0$ ), a $10 \mathrm{~L}$ IAPSO standard (salinity 10) and a 38H IAPSO standard (salinity $\sim 38$ ) are tested at the beginning of every batch of samples. P Series standards (salinity 35) should fall within an allowable error of \pm 0.003 . The average $z$ score over 8 rounds of QUASIMEME proficiency testing scheme exercises for salinity between October 2008 and May 2012 was 0.36, see Fig. 5. The MI is also accredited to ISO 17025 for salinity analysis in seawater and is audited by the INAB.

\subsection{Dissolved oxygen}

Dissolved oxygen (DO) samples were collected and analysed as per the standard operating procedure of Dickson (1995).

\subsubsection{Sampling}

DO samples were collected in $250 \mathrm{~mL}$ iodine bottles with plastic stoppers. All bottle-stopper pairs are individually calibrated and exact bottle volumes are used in final oxygen calculations. The bottle was filled from the bottom using silicone tubing, care was taken to minimize bubbles when filling and the water was overflowed by 3 flask volumes. Two millimetres of the pickling reagents, $\mathrm{MnCl}_{2}$ (no. 1) and $\mathrm{NaOH} / \mathrm{NaI}$ (no. 2), were added immediately to the sample, before carefully inserting the stopper and inverting the bottle several times. After the precipitate had settled at least half way, the bottle was shaken again. Samples were then stored in a cool dark location until titration, which was mostly carried out within $12 \mathrm{~h}$ of sampling.

\subsubsection{Analysis}

Oxygen samples were analysed using a modified Winkler method (Dickson, 1995), where the titration is carried out in the sample bottle. The sample is first acidified with sulfuric acid $\left(\mathrm{H}_{2} \mathrm{SO}_{4}\right)$ to a $\mathrm{pH}$ between 1 and 2.5 , which dissolves the hydroxide precipitates, and iodide ions added by reagent no. 2 are oxidized to iodine by the manganese (III) ions, which are reduced to $\mathrm{Mn}$ (II) ions in the process. In the final step, the iodine is reduced to iodide by titration with sodium thiosulfate, the amount of iodine generated, which is equivalent to the amount of oxygen in the sample, is determined by the amount of thiosulfate required to reach the endpoint. A Metrohm 848 Titrino Plus, with a Metrohm combined Pt electrode was used to determine the endpoint, i.e. potentiometric endpoint determination, measuring the change in redox potential of the sample, which reaches a minimum at the endpoint (Furuya and Harada, 1995). This method of determination was also used effectively by numerous WOCE cruises in the Atlantic and Pacific oceans, and also on some Hawaii Ocean Time Series (HOT) cruises (http://www.soest.hawaii.edu/HOT_WOCE/).

\subsubsection{Oxygen quality control}

Before titration of the samples, duplicate reagent blanks were determined and duplicate standardization of the sodium thiosulfate titrant was carried out. The reagent blank should ideally be less than $0.01 \mathrm{~mL}$, while the duplicate thiosulfate standardization should typically fall within $0.002 \mathrm{~mL}$ of each other (Dickson, 1995). Standardization of the thiosulfate is carried out in precisely the same conditions that the samples are analysed under so that any iodine lost through the volatilization or gained by the oxidation of iodide while analysing the seawater samples is compensated for with similar errors occurring during the standardization procedure (Knapp et al., 1989). Precision of the samples is estimated by running duplicate samples every $10-15$ samples.

\subsection{Secondary quality control}

Secondary QC was carried out on all four data sets using cross-over analysis (Tanhua, 2010; T. Tanhua and S. Lauvset, personal communication, 2013) with other data sets in the northeastern Atlantic in the Global Ocean Data Analysis Project (GLODAP) (Key et al., 2004) and CARbon dioxide IN the Atlantic Ocean (CARINA) (Key et al., 2010). Crossover analysis is an objective comparison of deep water data (in this case below $1500 \mathrm{~m}$ ) from one cruise with data 
from other cruises in the same area to quantify systematic biases in the data set (Tanhua, 2010). Results from the Rockall Trough should be approached with caution as there is natural oceanographic variability in this region. In all four Rockall surveys (2009-2012) there appears to be a negative offset in salinity (of approx. 0.01 each year), along with silicate $\left(\sim 1 \mu \mathrm{molkg} \mathrm{kg}^{-1}\right)$, relative to other cruises in GLODAP and CARINA. However, we believe that the change in salinity is natural and may suggest deeper water with more northerly component (lower salinity, lower nutrients and higher oxygen - all of which were observed in recent years). There were no adjustments required for the DIC and TA data, except for the 2009 TA which showed a negative offset of $11 \mu \mathrm{mol} \mathrm{kg}{ }^{-1}$. A very small portion of this may be related to the lower salinity observed, however such a large difference is unlikely to be true. This negative offset in the 2009 TA data had previously been observed through the water column (therefore not due to $\mathrm{CaCO}_{3}$ formation) and so was not included in McGrath et al. (2012a). Preliminary results suggest that this parameter will be adjusted in the second version of the GLODAP database, which is currently being developed.

\section{Data access}

The 2009-2012 data sets are currently available on CDIAC database (http://cdiac.ornl.gov/ftp/oceans/Rockall_Trough/), and discussed in McGrath et al. (2012a) and (2012b). The data sets will also be included in GLODAP version 2.0.

Acknowledgements. We would like to thank our colleagues at the Marine Institute, Ireland and at the National University of Ireland, Galway, that have contributed to the data collection both at sea and in the laboratory. We also thank the crew of the RV Celtic Explorer, who assisted us in our data collection across the Rockall Trough. We sincerely thank Toste Tanhua at GEOMAR Helmholtz-Zentrum für Ozeanforschung Kiel, and Siv Lauvset at Bjerknes Centre for Climate Research, University of Bergen, for carrying out and discussing the secondary quality control of the data. We thank João Almeida at NUIG for sharing his results from SIO that were used in the inter-laboratory comparison and thank staff at SIO for the analysis of the cross-validation batch of CE11001 samples.

Edited by: R. Key

\section{References}

Babulak, S. W. and Gildenberg, L.: Automated determination of silicate and carbonates in detergents, J. Am. Oil Chem. Soc., 5, 296-299, 1973

Boltz, D. F. and Mellon, M. G.: Spectrophotometric determination of phosphate as molydophosphoric acid, Anal. Chem., 20, 749751,1948
Cofino, W. P. and Wells, D. E.: Design and Evaluation of the QUASIMEME Inter-Laboratory Performance Studies: A test case for robust statistics, Mar. Pollut. Bull., 29, 149-158, 1994.

Dickson, A. G.: An exact definition of total alkalinity and a procedure for the estimation of alkalinity and total inorganic carbon from titration data, Deep-Sea Res. Pt. I, 28, 609-623, 1981.

Dickson, A. G.: Determination of dissolved oxygen in sea water by Winkler titration, WOCE Operations Manual. Part 3.1.3 Operations \& Methods, WHP Office Report WHPO 91-1, 1995.

Dickson, A. G., Afghan, J. D., and Anderson, G. C.: Reference materials for oceanic $\mathrm{CO}_{2}$ analysis: a method for the certification of total alkalinity, Mar. Chem., 80, 185-197, 2003.

Dickson, A. G., Sabine, C. L., and Christian, J. R.: Guide to best practices for ocean $\mathrm{CO}_{2}$ measurements, PICES Special Publication, 3, 1-191, 2007.

EPA: Method of chemical analysis of water and wastes. Off Technological Transfer, Environmental Protection Agencym Washington D.C., 1974.

Furuya, K. and Harada, K.: An Automated Precise Winkler Titration for Determining Dissolved Oxygen on Board Ship, J. Oceanogr., 51, 375-383, 1995.

Grasshoff, K., Ehrhardt, M., Kremling, K., and Almgren, T.: Methods of seawater analysis, 3rd Edn., Wiley-VCH, 1999.

Greenberg, A. E., Jenkins, D., and Connors, J. J.: Standard Methods for the Examination of Water and Wastewater, APHA-AWWAWPCF, 1980.

ISO 13395: Determination of nitrite nitrogen and nitrate nitrogen and the sum of both by flow analysis (CFA) and spectrometric detection, 1996.

ISO 15681-2: Determination of ortho phosphate and total phosphorus conents by flow analysis, Part 2: Method by continuous flow analysis (CFA), 2003.

ISO 16264: Determination of soluble silicals by CFA and photometric detection, 2002.

Johnson, K. M., Sieburth, J. M., Williams, P. J. L., and Brändström, L.: Coulometric total carbon dioxide analysis for marine studies: Automation and calibration, Mar. Chem., 21, 117-133, 1987.

Johnson, K. M., Wills, K. D., Butler, D. B., Johnson, W. K., and Wong, C. S.: Coulometric total carbon dioxide analysis for marine studies: maximizing the performance of an automated gas extraction system and coulometric detector, Mar. Chem., 44, 167-187, 1993.

Key, R. M., Kozyr, A., Sabine, C. L., Lee, K., Wanninkhof, R., Bullister, J. L., Feely, R. A., Millero, F. J., Mordy, C., and Peng, T. H.: A global ocean carbon climatology: Results from Global Data Analysis Project (GLODAP), Global Biogeochem. Cy., 18, GB4031, doi:10.1029/2004GB002247, 2004.

Key, R. M., Tanhua, T., Olsen, A., Hoppema, M., Jutterström, S., Schirnick, C., van Heuven, S., Kozyr, A., Lin, X., Velo, A., Wallace, D. W. R., and Mintrop, L.: The CARINA data synthesis project: introduction and overview, Earth Syst. Sci. Data, 2, 105121, doi:10.5194/essd-2-105-2010, 2010.

Knapp, G. P., Stalcup, M. C., and Stanley, R. J.: Dissolved oxygen measurements in sea water at the Woods Hole Oceanographic Institution, WHOI Technical Report, WHOI-89-23, 14 pp., 1989.

McGrath, T., Kivimae, C., Tanhua, T., Cave, R. R., and McGovern, E.: Inorganic carbon and $\mathrm{pH}$ levels in the Rockall Trough 19912010, Deep-Sea Res. Pt. I, 68, 79-91, 2012a. 
McGrath, T., Nolan, G., and McGovern, E.: Chemical characteristics of water masses in the Rockall Trough, Deep-Sea Res. Pt. I, 61, 57-73, 2012b.

Mintrop, L., Pérez, F. F., Gonzalez-Dávila, M., Santana-Casiano, J. M., and Körtzinger, A.: Alkalinity determination by potentiometry: intercalibration using three different methods, Cienc. Mar., 26, 23-37, 2000.

Navone, R.: Proposed method for nitrate in potable waters, American Journal Water Work Association, 56, 781-783, 1964.

O’Dowd, C., Cave, R., McGovern, E., Ward, B., Kivimae, C., McGrath, T., Stengel, D., and Westbrook, G.: Impacts of Increased Atmospheric $\mathrm{CO}_{2}$ on Ocean Chemistry and Ecosystems, Marine Research Sub-Programme (NDP 2007-2013) Series, Marine Institute, ISSN: 2009-3195, 2011.
Smith, J. D. and Milne, P. J.: Spectrophotometric determination of silicate in natural waters by formation of $\alpha$-molybdosilicic acid and reduction with tin(IV)-ascorbic acid-oxalic mixture, Anal. Chim. Acta, 123, 263-270, 1981.

Tanhua, T.: Matlab Toolbox to Perform Secondary Quality Control (2nd QC) on Hydrographic Data. ORNL/CDIAC-158, Carbon Dioxide Information Analysis Center, Oak Ridge National Laboratory, U.S. Department of Energy, Oak Ridge, Tennessee, doi:10.3334/CDIAC/otg.CDIAC_158, 2010.

Walinga, I., van Vark, W., Houba, V. J. G., van der Lee, J. J.: Plant analysis procedure, Part 7, Department of Soil Science and Plant Nutrition, Wageningen Agricultural University, 197-200, 1989. 